\title{
The National Budget Circular 461: Emerging trends in Philippines higher education promotion system
}

\author{
Francisco D. Esponilla II ${ }^{1}$, Lean Karlo S. Tolentino ${ }^{2}$, Cherrypyn B. Barbacena ${ }^{3}$, Apollo P. Portez ${ }^{4}$ \\ ${ }^{1}$ University Research and Development Services, Technological University of the Philippines, Philippines \\ ${ }^{2}$ University Extension Services, Technological University of the Philippines, Philippines \\ ${ }^{3,4}$ Professional Industrial Education Department, Technological University of the Philippines, Philippines
}

\begin{tabular}{l} 
Article Info \\
\hline Article history: \\
Received Jun 30, 2020 \\
Revised Oct 9, 2020 \\
Accepted Oct 29, 2020 \\
\hline
\end{tabular}

\section{Keywords:}

Delphi model technique

Descriptive research

Faculty engagement

Mixed method research design

National budget

\begin{abstract}
This research aimed to identify trends on promotion challenges and concerns $(\mathrm{CaCs})$ encountered by the faculty members in selected State universities and colleges (SUCs) in the Philippines. To specifically identify significant $\mathrm{CaCs}$, the study employed the mixed-method research design utilizing the delphi model technique for data collection. Thematic data coding was thoroughly conducted to come up with a consensus from the experts in the field of promotion in higher education. There were 10 focal persons from the SUCs in the national capital region (NCR) purposively chosen as the study participants. The identified challenges and concerns as the trend indicators were categorized into themes such as appreciation of documents, faculty engagement for promotion, information dissemination, schedule of implementation, responsiveness of the national budget circular No. 461 (NBC 461) focal persons to promotion-related concerns, faculty engagement to promotion, and stakeholder's engagement to promotion. These indicators would be a relevant implication to the holistic and a uniform faculty promotion scheme in higher education institutions of the country. Hence, the result of the study shall be utilized by the SUCs policymakers in crafting the standardized NBC 461 policy guideline that is inclusive for implementing equal promotion opportunity as well as job security.
\end{abstract}

This is an open access article under the CC BY-SA license.

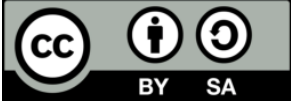

\section{Corresponding Author:}

Francisco D. Esponilla II,

University Research and Development Services,

Technological University of the Philippines,

Ayala Boulevard, Ermita, Manila 1000, Philippines.

Email: francisco_esponilla@tup.edu.ph

\section{INTRODUCTION}

State universities and colleges (SUCs) in the Philippines, the current promotion is based on the National Budget Circular 461 (NBC 461, 1998). The mode of promotion scheme employed is a mass promotion based on the guidelines by the NBC 461 jointly approved by the Philippine association of state colleges and universities (PASUC) approved by the commission on higher education (CHED) and was funds allocated by the department of budget and management (DBM). Mass promotion in the sense that, all faculty members in the SUCs were given the opportunity to be promoted during and within the promotion cycle. Thus, promotion is directly influenced by an individual employee's effort [1] to conform to the specifications as stipulated in the implementation guidelines. It is an extrinsic factor that serves as a motivating indicator for a faculty member's growth and development in their respective fields of expertise [2]. Further, promotion boosts employee's morale and it recognizes the faculty share to their respective university performance for productivity $[3,4]$. 
Promotion remains a critical issue for every organization [5]. According to Noor, et al. [6], as resulted from their research on Ph.D. and non-Ph. D faculty in the universities in Pakistan, recommended the flexible promotion scheme, seeking employees' point of view, and reward incentives for every qualified faculty member. Noor, et al. [6] added that is the exemplary performance in the discharge of duties and responsibilities contributory to the organization's productivity which corresponds to valued recognition by the employer. Beheshtifar \& Nazarian [4] believed that intervention between the employee and the management stakeholders is crucial to employee's performance results. Promotion is about expectation and individual performance granted in consideration of the consistent hard work and performance with the associated level of effort based on merit set forth by the authority according to Pradhan and Jena [7]. The merit system for job performance is a human resource initiative that an employee is able to fulfill the role and expectations required of the job correlating to employees' job portfolio [8-10]. Performance-based promotion is about employee's potential, employers redound to the principle of fair promotion practice. This is incognizant to the substantial equal opportunity that all employees were given equal chances of being promoted and that employee's rights and welfare is not compromised [11]. However, failure of the management to give due credit to the performance of the employees affects job performance [12, 13], satisfaction [5, 14], commitment [15], and equal opportunity [16].

The underlying challenges and concerns $(\mathrm{CaCs})$ emerging during the implementation of faculty promotion in the state universities and colleges (SUCs) were considered. It is crucial in addressing issues on faculty professional growth and development [17], employee and employer engagement [18] and differing interpretations of promotion and rewarding schemes $[12,16]$.

This mixed-method Delphi study was aimed to explore the national budget circular 461 (NBC 461) implementation guidelines. In particular, the study sought to identify various NBC 461 challenges and concerns $(\mathrm{CaCs})$ manifested in the promotion particularly on the areas of the common criteria for evaluation (CCE) and the qualitative contribution evaluation (QCE) which were enumerated by the NBC 461 Focal Persons from the various state universities and colleges (SUCs) in the national capital region. The identified NBC $461 \mathrm{CaCs}$ were conceptualized from the literature about promotion implementation [19-26]. These includes appreciation of documents [27], information dissemination [28-30], responsiveness of the NBC 461 focal persons to faculty concerns $[11,12,16]$, schedule of implementation [31-34], faculty engagement to promotion [18, 35-38], and stakeholders' engagement [5, 39-42].

Although there were many attempts to revisit the NBC 461 guidelines which were first started in June 1989, the later output was implemented in 2005. Evident are the applications of the new procedures and rectifications applied during the promotion implementation, but there are no documents like a memorandum, a policy, and or a resolution to substantiate a clearer understanding of the implementation methodologies being disseminated among the implementing sectors. To this effect, the researcher sought that this exploratory research would likewise serve to revisit the national budget circular 461 after 29 years to document temporal gaps on new updates and changes in the specific guidelines in support of the proposed standardized policy for future promotion implementation in the SUCs.

\section{RESEARCH METHOD}

The mixed-method Delphi research design employed the exploratory sequential mixed-method approach. This means that the initial phase of the collection of data and analysis was qualitative followed by a phase of quantitative data collection and analysis [43,44]. Mixed method research often referred to as the "third methodological orientation" [45] draws the strengths of both qualitative and quantitative research.

A qualitative-quantitative data analysis with the Delphi model technique in soliciting the consensus of the experts in the NBC 461 promotion scheme in the state universities and colleges (SUCs) was likewise utilized. The qualitative phase was the in-depth data analysis through open coding [46-49], selective coding [49-51], and axial coding [52-54] in the Delphi round 1 survey results. While the quantitative phase was on the treatment of the quantifiable data of the delphi round 2 results which employ the means, standard deviation, coefficient of variation, interquartile range. However, the Delphi round 3 results cannot be considered as quantitative because the average percentage of majority opinion (APMO) characterized by a dichotomous response (agree or disagree) is only used to explain the modal occurrence of the majority opinion of the participants. The method employed was Creswell's [55] methods of research design as shown in Figure 1. 




Figure 1. Creswell's mixed-method research design

On the other hand, Delphi model technique is an interactive and systematic technique in incorporating collective decisions from the experts with justifications corresponding to their judgment of the underlying indicators [56] towards consensus building [57]. The exploratory-sequential is said to be qualitative since the pool of experts is the one that provides for an indicator. In this study, the indicators are referred to as challenges and concerns $(\mathrm{CaCs})$. On the other hand, the research is quantitative because the Delphi Model Technique assigns the descriptive data with numerical interpretations for an in-depth analysis of the indicators particularly in the 2nd and 3rd Delphi Stages where consensus-building of qualitative data was undertaken.

As described by Green [58], Delphi technique is important in forming guidelines, standards, and forecasting trends which can be used for decision making, policymaking, and predicting future implications to higher educations in (a) cost-effectiveness, (b) cost-benefit analysis, (c) curriculum and campus planning, and (d) university-wide educational goals and objectives. The Delphi model technique is a method of eliciting and refining experts' judgments [59]. According to McMillan, et al. [60], it is a step-by-step process that aims to achieve agreement or convergence of opinion around a particular topic. Fefer, et al. [61] added that the consolidated agreements are the collective results from a series of rounds or stages of consensus which resulted from the opinions of the experts based on their experiences.

Therefore, the study is an exploratory sequential design that clarifies and defines a problem for better analysis [55]. Since the exploratory design does not provide conclusive evidence for analyzing a given problem, a Delphi Model Technique was utilized to be the model for the current research inquiry. Further, an exploratory sequential mixed method was utilized in order to broadly explore the actual manifestation of experiences of the participants [43].

Furthermore, the research study made use of the mixed-method research for collecting, analyzing, and interpreting data. This process employed in social research was referred by the pragmatist view of conducting research [62-66]. Pragmatism as a world view paradigm is a problem-oriented philosophy that underpins mixed-method research [67] rather than choosing between a qualitative or a quantitative research design. The social pragmatist researchers believed that employing both qualitative and quantitative research designs complements research strengths $[65,68,69]$. In terms of the pragmatic application to social research, the investigation is founded on the nature of human experience in providing practical solutions to the identified problems [55, 70-72].

A purposive sampling of the NBC 461 Focal Persons which included the seven (7) University Review Committee (URC) reviewers and evaluators from the respective SUCs in the National Capital Region (NCR) and three (3) Zonal Reviewers from the PASUC National were the study participants. To avoid bias in the expert's subjective opinion on the challenges and concerns [73, 74], the consolidated challenges and concerns established by the NBC 461 Focal Persons were subjected to a consensual level of agreement by the same participants for purposes of finalization of the proposal for inclusion to the current NBC 461 implementing guideline.

There were three types of validated survey questionnaires prepared for the Delphi stages: 1) A survey questionnaire to solicit the challenges and concerns experienced by the NBC 461 focal persons; 2) A survey questionnaire containing the solicited challenges and concerns identified by the NBC 461 focal persons; 3) A final survey questionnaire containing the initially consolidated challenges and concerns ranked by the NBC 461 focal persons for determining the final consensus.

In consideration with the ethical standard in qualitative research, any information about the NBC 461 Focal Persons was represented by the Participants respective SUCs of affiliation. Participants aside from the three (3) experts from the NCR zonal center are the various SUCs in the NCR which include the Eulogio "Amang" Rodriguez Institute of Science and Technology (EARIST), Marikina Polytechnic College (MPC), Philippine Normal University (PNU), Philippine State College of Aeronautics (PhilSCA), Polytechnic University of the Philippines (PUP), Rizal Technological University (RTU), and Technological University of the Philippines (TUP). 
In the planning stage, an initial scanning for the realization of the study has been conducted in the presence of the university review committee (URC) members who served as NBC 461 focal persons from other SUCs in the national capital region. The purpose of initial scanning is to solicit partial commitment of the URC focal persons to participate as participants of the study. As selected participants of the study, the NBC 461 Focal Persons will share their common observations, issues, and experiences in the implementation of the NBC 461 promotion as challenges and concerns in their respective individual SUC of affiliation. Inspired by the positive response from the expected pool of informants, the main survey instrument explored the challenges and concerns regarding the implementation of NBC 461 as shown in Table 1.

Table 1. Challenges and concerns ( $\mathrm{CaCs}$ ) of the survey content of the instrument

\begin{tabular}{ccc}
\hline Common Criteria for Evaluation (CCE) & Qualitative Contribution Evaluation (QCE) & Implementation \\
\hline $\begin{array}{c}\text { Experience and length of service. } \\
\text { Professional development, } \\
\text { achievements and honors. }\end{array}$ & Instruction-teaching effectiveness. & $\begin{array}{c}\text { Schedule of Implementation. } \\
\text { Information Dissemination. }\end{array}$ \\
& Research. & $\begin{array}{c}\text { Appreciation of documents. } \\
\text { Extension }\end{array}$ \\
& & $\begin{array}{c}\text { Responsiveness of the of the NBC 461 focal } \\
\text { persons to Promotion-Related Concerns. }\end{array}$ \\
\hline
\end{tabular}

The Delphi stage 1 refers to the first round NBC 461 URC focal person's solicitation of challenges and concerns based on their experiences and those experiences relayed by their respective faculty members in their respective SUCs. After the first round, the gathered data was consolidated (listed together) ready for the Delphi stage 2 (2nd Round). The determined challenges and concerns were organized (structured) according to how the NBC 461 guideline is organized as indicators in the educational qualifications, experience and length of service, and professional development achievement and honors in the NBC 461 guidelines, which also included the implementation phase. A 6-point Likert scale was utilized for purposes of rating the identified challenges and concerns is incorporated in the 2 nd round survey for the initial consolidation round. The identified initial rated challenges and concerns were subjected to the quantitative treatment (interquartile and covariance). The extracted results were consolidated ready for the final Delphi stage to solicit the final consensus on the challenges and concerns utilizing the average percentage of the majority opinion (APMO). The result of the APMO signifies the final consensus of the challenges and concerns to be included in the proposed standardized implementing guidelines.

\subsection{Data analysis and treatment}

The following data analysis and treatment of the Delphi model technique was utilized.

\subsubsection{Delphi stage 1 (Experts solicitation of challenges and concerns)}

The researcher administered the survey form to the selected NBC 461 URC focal persons in the seven SUCs in the NCR, including the three (3) Regional NBC 461 focal persons representing the respective zonal centers. A face-to-face administration of the survey questionnaire was conducted to address the openended question(s) in the survey questionnaire and initially took details of the participants' profile. After the face-to-face interview, the questionnaire was left to NBC 461 focal persons for them to review their responses. Follow-up and retrieval of the survey were done after a week through Facebook messenger, mobile call and text message, and email conversation.

After retrieval, the collected responses from the pool of NBC 461 focal persons were clustered into themes. Though the survey questionnaire was temporarily organized according to how the NBC 461 implementing guidelines is categorized, the later was then coded to come up with a themes according to implementation requirements being the focus of inquiry which is about the challenges and concerns aired by the faculty members to their respective NBC reviewer/evaluators in preparation for the semi-structured survey questionnaire which served as the main instrument for the delphi stage 2.

The initial thematic identification was taken from what has transpired in the arguments of the related literature and studies which resulted in the first four themes already included in the Round 1 open-ended question. The thematic coding of the identified challenges and concerns was done through filtering. Filtering of the challenges and concerns was done through reading and analyzing each statement and grouping them into corresponding themes. To avoid duplication of opinion, statements with the same thoughts and meanings were consolidated as one to reduce the number of identified challenges and concerns.

The themes included the following: 1) Schedule of implementation, 2) Information dissemination, 3) Appreciation of documents, and 4) Responsiveness of the NBC 461 focal persons. While during the thematic coding (filtering) of the data another two themes were culled-out to include 1) Faculty engagement to NBC 
461 compliance, and 2) Stakeholders' engagement in promotion implementation. Therefore, the main instrument of the second round contains the five major themes for evaluation of the NBC 461 focal persons based on the agreement as a manifestation of experiences during the previous NBC 461 promotion implementation.

\subsubsection{Delphi stage 2 (Experts consensus)}

The responses gathered from the Delphi stage 1 was listed accordingly and organized according to a semi-structured survey questionnaire for evaluation based on agreement of the consolidated challenges and concerns by the NBC 461 University review committee (URC) focal persons. Following the rating scale in shown in Table 2. The NBC 461 URC focal persons were asked to rate the consolidated thematic clusters based on the level of their agreement to the reverted negative statements into a suggestion/recommendation statement from the identified NBC 461 challenges and concerns.

Table 2. Interpretation of the agreement of the identified NBC 461 implementation challenges and concerns

\begin{tabular}{cc}
\hline Rating Scale & Description \\
\hline 6 & Strongly Agree \\
5 & Agree \\
4 & Moderately Agree \\
3 & Somewhat Disagree \\
2 & Disagree \\
1 & Strongly Disagree \\
\hline
\end{tabular}

The data collected data was subjected to a third interquartile rage (3rdIQR) treatment to determine inclusion of the identified thematic clusters to the proposed standardized NBC 461 implementing guidelines. Suggestion/recommendation statements in each theme included in the proposal are those falls within or below the exact value of 1 Interquartile range. The formula for Interquartile range is:

$$
\mathrm{IQR}=\mathrm{Q}_{3}-\mathrm{Q}_{1}
$$

Where, $\mathrm{Q}_{3}$ is refers to the upper quartile and $\mathrm{Q}_{1}$ refers to the lower quartile. To extract Values of $\mathrm{Q}_{3}$ and $\mathrm{Q}_{1}$, the following formulas are used

$$
\begin{aligned}
& Q_{1}=\frac{1}{4}(n+1) \text { th value where } n \text { is the number of data values in the data set. } \\
& Q_{3}=\frac{3}{4}(n+1) \text { th value where } n \text { is the number of data values in the data set. }
\end{aligned}
$$

Since each participant would have their own means and standard deviations for each challenges and concerns, the researcher also analyzed the data utilizing the coefficient of variation (CV) for the challenges and concerns that falls below or equivalent to $\mathrm{CV}=50 \%$ were the basis to determine the reliability of the initial consensus. The formula for Coefficient of Variation is:

$$
\mathrm{CV}=\frac{\text { Standard Deviation }}{\text { Mean }} \times 100 \%
$$

\subsubsection{Delphi stage 3 (Final stage: Consensus building)}

After consolidating the initial consensus, the third time, the list of the ranked Challenges and Concerns (passed the IQR value of 1 or less with $\mathrm{CV}$ value of $50 \%$ equivalent or below) for inclusion to the NBC 461 guideline was presented to the NBC 461 URC focal persons for final consensus rating. To address challenges and concerns with lower extreme values which were found to be important, the researcher intends to include it to the final questionnaire for this stage (Delphi stage 3). Since this stage is for re-evaluation, the initial list with the final ratings of the NBC 461 URC focal persons was retrieved the same week after administration. The questionnaire for this stage was sought to build a final consensus of the identified NBC 461 implementation challenges and concerns. The data collected was subjected to the calculation of the (APMO) utilizing the following formula: 


$$
\mathrm{APMO}=\frac{\text { Majority agreements }+ \text { Majority disagreement }}{\text { Total opinion expressed }} \times 100 \%
$$

The APMO cut off was not intended for removal of the identified challenges and Concerns with the $50 \%$ cut off rate but was treated as follows:

$50 \%$ above cut off rate - priority for inclusion to the Standard Implementation

$50 \%$ below cut off rate - Secondary for inclusion to the Standard Implementation

After the APMO cut-off rate was identified, the responses were finally consolidated which served as the main subject of the proposal for inclusion to a standardized NBC 461 Guidelines.

\section{RESULTS AND DISCUSSION}

Challenges and concerns $(\mathrm{CaCs})$ in this study is referred to as the indicators of promotion trends in higher education. The Delphi round 1 resulted to a 129 possible challenges and concern initially identified by the NBC 461 focal persons as seen in Table 3 and Table 4. The final Delphi round which marked the 3rd round of the Delphi model technique revealed that there is a universal consensus of the agreement on the determined NBC 461 challenges and concerns. With the saturation of filtering the commonalities of codes in the axial coding stage, all were acknowledged and was included in the final thematic clusters of the study presented in Table 4.

Table 3. Interpretation of the agreement of the identified NBC 461 implementation challenges and concerns

\begin{tabular}{ccc}
\hline Main Themes & Sub-themes & Percent \\
\hline Documentation & 53 & $41 \%$ \\
University Responsibility & 34 & $26 \%$ \\
Information & 11 & $9 \%$ \\
Query & 12 & $9 \%$ \\
Implementation & 10 & $8 \%$ \\
Faculty Responsibility & 9 & $7 \%$ \\
Total Count: & 129 & $100 \%$ \\
\hline
\end{tabular}

Table 4. Summary of the NBC 461 challenges and concerns reaching consensus

\begin{tabular}{rcccc}
\hline Challenges and Concerns & Mean & SD & IQR & CV \\
\hline Information Dissemination & 5.48 & 0.40 & 0.46 & 0.07 \\
Schedule of Implementation & 5.48 & 0.48 & 0.56 & 0.09 \\
Stakeholders Engagement to Promotion Implementation & 5.31 & 0.42 & 0.5 & 0.08 \\
Faculty Engagement for Promotion & 5.30 & 0.45 & 0.54 & 0.08 \\
Appreciation of Documents & 5.25 & 0.44 & 0.39 & 0.08 \\
Responsiveness of the NBC 461 Focal Persons to Faculty Concerns & 5.20 & 0.62 & 0.75 & 0.12 \\
Grand Mean: & 5.34 & 0.47 & 0.53 & 0.09 \\
\hline
\end{tabular}

Legend:

a. Cut-off point: $I Q R \leq 1$

b. Cut-off point: $C V \leq 50 \%$

c. Rating Scale: $6=$ Strongly Agree, $5=$ Agree, $4=$ Moderately Agree, $3=$ Somewhat Disagree, $2=$ Disagree

1 = Strongly Disagree

The specific thematic clusters revealed in the categories of the challenges and concern are information dissemination (Mean $=5.48$ ), schedule of implementation (Mean = 5.48), stakeholders' engagement $($ Mean $=5.31)$, faculty engagement to promotion (Mean $=5.30)$ appreciation of documents $($ Mean $=5.25)$, and responsiveness of the NBC 461 Focal Persons to promotion-related concerns $($ Mean $=$ $5.20)$.

The final round of the delphi inquiry revealed a universal agreement with the additional of 2 indicators emerged (increase points for community service and clarification on the "whichever is lower") during the delphi round 2 to a total of 55 NBC 461 challenges and concerns which were finally determined by the NBC 461 focal persons who served as the participants of the study. Supported by the literature and the results of the investigations of the delphi rounds, it was scholarly safe to finally recommend the foregoing framework as input to a proposed standardized NBC 461 guidelines as a reference in the local, regional, and national NBC 461 promotion as seen in Figure 2. 


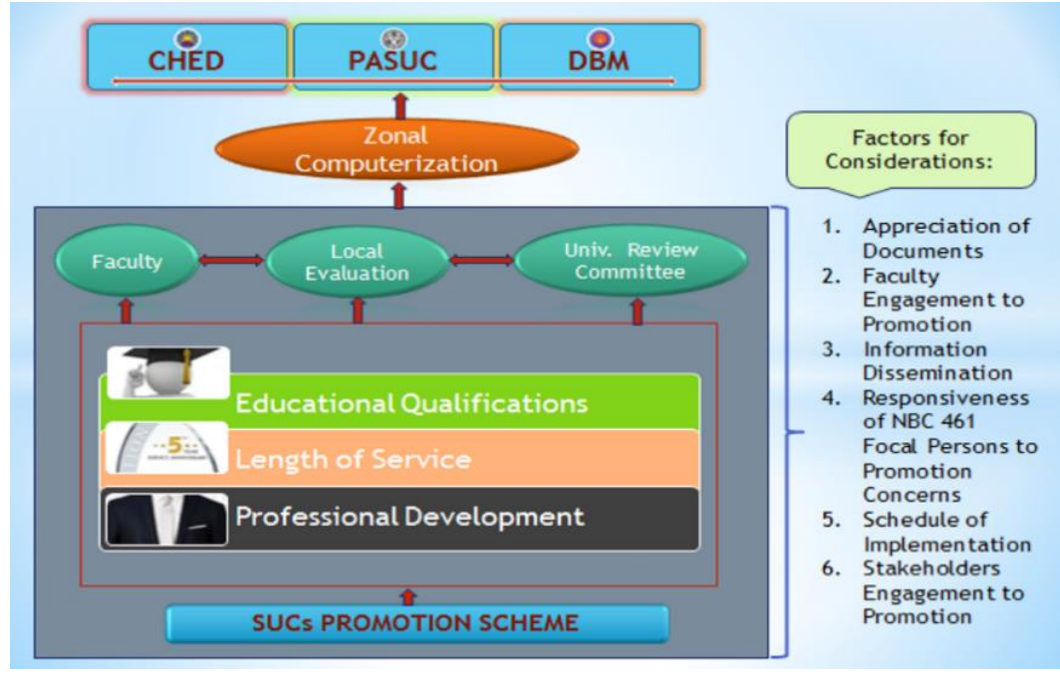

Figure 2. Factors to consider in the national budget circular 461 implementation guidelines (Originally proposed by the researchers)

Reflected in Figure 2 is the promotion scheme of the SUCs in the Philippines particularly the national budget circular 461 (NBC 461). This NBC 461 has guidelines to follow in the evaluation of the performance of the faculty members in terms of professional development, length of service, and educational qualifications. Performance may be validated by considering the identified promotion trends emerged from the result of the current research study, namely, appreciation of documents, faculty engagement to the promotion, information dissemination, faculty responsiveness to promotion concerns, schedule of implementation, and stakeholders' engagement to promotion. The result of the NBC 461 will be submitted to the DBM for funding. Thus, the CHED and PASUC jointly work together with the DBM for validation, approval, and release of funding to the SUCs for the implementation of the NBC 461. A longitudinal study can also be conducted to further investigate suitable schemes contributory to the knowledge-based promotion implementation.

\section{CONCLUSION}

The process of determining the consensus on the NBC 461 implementing guidelines challenges and concerns $(\mathrm{CaCs})$ employed in this study with the delphi model technique as the primary method of collecting data, provides an articulation of the CaCs experienced by the faculty members in the state universities and colleges (SUCs). These CaCs are the indicators of promotion trends that would be considered as factors to consider in crafting a standardized faculty promotion guideline. Figure 2 represents the proposed framework model that the SUCs may use as a guide in their NBC 461 promotion. The same framework which included the six (6) identified challenges and concerns tagged as factors for considerations may be utilized by the commission on higher education and the department of budget and management in drafting of the new and updated NBC 461 Standardized Guidelines.

The consensus of the NBC 461 Focal Persons as participants of the study is considered as significant factors in the implementation of the promotion scheme in the state universities and colleges (SUCs). Therefore, their consensus revealed the promotion trends of their respective home SUCs where both public and private higher education institutions (HEIs) may be adapted. Hence, the NBC 461 policymakers may use the framework in the drafting of the latest NBC 461 Implementing guidelines that is suited to the current promotion trends in the HEIs.

The consensus of the NBC 461 Focal Persons was likewise established by qualitative data analysis (data coding) and inferential statistical treatment of quantifiable data. Hence, the paper hereby recommends that the final consensus of the NBC 461 determined challenges and concerns framework as seen in Figure 2 be considered by the higher education authorities in the crafting of standardized promotion guidelines for SUCs in the Philippines. 


\section{REFERENCES}

[1] A. Suhail and A. Azhar, "Managing Human Resources in Public Health Care System in South Asia: Case Study of Pakistan," South Asian Journal of Human Resources Management, vol. 3, no. 1, pp. 75-83, 2016.

[2] G. P. Latham, "Goal setting: A five-step approach to behavior change," Organizational Dynamics, vol. 32, no. 3, pp. 309-318, 2003.

[3] M. V. Gerven and M. Nygård, "Equal treatment, labor promotion, or social investment? Reconciliation policy in Finnish and Dutch coalition programs 1995-2016," European policy analysis, vol. 3, no. 1, pp. 125-145, 2017.

[4] M. Beheshtifar and R. Nazarian, "Role of occupational stress in organizations," Interdisciplinary Journal of Contemporary Research in Business, vol. 4, no. 9, pp. 648-657, 2013.

[5] Zahid, N.I. and Ullah, K.A., "Impact of job promotion and job advancement on job satisfaction in universities of KPK province of Pakistan," 2015

[6] Z. Noor, A. U. Khanl, and I. Naseem, "Impact of job promotion and job advancement on job satisfaction in universities of KPK Province of Pakistan," Science International Journal (Lahore), vol. 27, no. 2, pp. 1499-1505, 2015.

[7] R. K. Pradhan and L. K. Jena, "Employee performance at workplace: Conceptual model and empirical validation," Business Perspectives and Research, vol. 5, no. 1, pp. 69-85, 2017.

[8] D. Hellriegel, et al., Management: Second South African Edition. Cape Town: Oxford University Press Southern Africa, 2004.

[9] D. Fay and H. Lührmann, "Current themes in organizational change," European journal of work and organizational psychology, vol. 13, no. 2, pp. 113-119, 2004.

[10] T. S. Bateman and S. A. Snell, Management: Leading \& collaborating in a competitive world. McGraw-Hill, 2015.

[11] M. Bevir, Encyclopedia of Political Theory (1st Ed.), SAGE Publications, Inc., pp. 452-453, 2010.

[12] S. Moreau, "Discrimination as negligence," Canadian Journal of Philosophy, vol. 40, no. sup1, pp. 123-149, 2010.

[13] H. Noe, et al., Human Resource management: gaining a competitive advantage, (8th ed). New York, NY: McGraw-Hill Education, 2010.

[14] R. M. Foor and J. Cano, "Predictors of Job Satisfaction among Selected Agriculture Faculty," Journal of Agricultural Education, vol. 52, no. 1, pp. 30-39, 2011.

[15] B. Aziri, "Job satisfaction: A literature review," Management Research and Practice, vol. 3, no. 4, pp. 77-87, 2011.

[16] K. Lippert-Rasmussen, Born free and equal? A philosophical inquiry into the nature of discrimination. Oxford University Press, 2014.

[17] D. G. Buckman, A. D. Johnson, and D. L. Alexander, "Internal vs External Promotion: Advancement of Teachers to Administrators," Journal of Educational Administration, vol. 56, no. 1, pp. 33-49, 2018.

[18] J. Peklar and E. Boštjančič, "Motivation and life satisfaction of employees in the public and private sectors," Central European Public Administration Review, vol. 10, no. 3, pp. 57-74, 2012.

[19] O. Fevzi, "A framework to implement strategies in organizations," Management Decision, vol. 41, no. 9, pp. 871-882, 2003.

[20] J. M. Higgins, "The eight 'S's of successful strategy execution," Journal of Change Management, vol. 5, no. 1, pp. 3-13, 2005.

[21] F. Alamsjah, "Key success factors in implementing strategy: middle-level managers' perspectives," ProcediaSocial and Behavioral Sciences, vol. 24, pp. 1444-1450, 2011.

[22] T. Mwawasi, K. Wanjau, and M. Mkala, "Factors affecting implementation of operational strategies in NonGovernmental Organizations in Kenya," Global Journal of Human Resource Management, vol. 1, no. 4, pp. 10-19, 2013.

[23] N. Jiang and V. Carpenter, "A case study of issues of strategy implementation in internationalization of higher education," The International Journal of Educational Management, vol. 27, no. 1, pp. 4-18, 2013.

[24] S. A. Bolboli and M. Reiche, "A model for sustainable business excellence: implementation and the roadmap," The TQM Journal, vol. 25, no. 4, pp. 331-346, 2013.

[25] A. M. Pettigrew, The politics of organizational decision-making. Routledge, London, Tavistock, 2014.

[26] R. Obeidat, "A study of the implementation stage of strategic decisions in the banking sector in Jordan," Doctoral Dissertation, Durham University, Durham, 2008.

[27] B. Townley, "The institutional logic of performance appraisal," Organization studies, vol. 18, no. 2, pp. 261-285, 1997.

[28] C. Vidales Gonzáles, "From the consideration of communication as a field to the consideration of communication as a transdisciplinary concept: history, theory and objects of knowledge," Comunicación y sociedad, no. 30, pp. 45-68, 2017. [Online]. Available: http://www.academia.edu/36519670/From_the_consideration

[29] K. Miller, Organizational Communication: Approaches and Process, (6th Edition). Belmont, CA: ThompsonWardsworth, 2012.

[30] T. Cummings and C. Worley, Organizational development and change, 10th Edition. Nelson Education: Toronto, 2016.

[31] A. Iqbal, "Employee turnover: Causes, consequences and retention strategies in the Saudi organizations," The Business Review, Cambridge, vol. 16, no. 2, pp. 275-281, 2010.

[32] S. Brown, et al., "Workplace performance, worker commitment, and loyalty," Journal of Economics \& Management Strategy, vol. 20, no. 3, pp. 925-955, 2011.

[33] D. M. Kaplan, J. W. Wiley, and C. P. Maertz Jr., "The role of calculative attachment in the relationship between diversity climate and retention," Human Resource Management, vol. 50, no. 2, pp. 271-287, 2011. 
[34] P. M. Wegner, "The relationship between employee engagement and employee retention in an acute healthcare hospital," Doctoral dissertation, ProQuest Dissertations and Theses database, (UMI No. 3469938), 2011.

[35] J. Cao and D. Thomas, When developing a career path, what are the key elements to include? Cornell University, ILR School, 2013. [Online]. Available: http://digitalcommons.ilr.cornell.edu/student/43/

[36] I. Vardi and R. Quin, "Promotion and the scholarship of teaching and learning," Higher Education Research \& Development, vol. 30, no. 1, pp. 39-49, 2011.

[37] Y.C. Chi, "The study of human resource management of faculty in public universities in Taiwan," Journal of National Taichung University, vol. 25, no. 2, pp. 85-110, 2011.

[38] X. Qin, R. Ren, Z. X. Zhang, and R. E. Johnson, "Fairness heuristics and substitutability effects: inferring the fairness of outcomes, procedures, and interpersonal treatment when employees lack clear information," The Journal of Applied Psychology, vol. 100, no. 3, pp. 749-766, 2014.

[39] I. Cojuharenco and D. Patient, "Workplace fairness versus unfairness: Examining the differential salience of facets of organizational justice," Journal of Occupational and Organizational Psychology, vol. 86, no. 3, pp. 371-393, 2013.

[40] J. M. Millán, J. Hessels, R. Thurik, and R. Aguado, "Determinants of job satisfaction: a European comparison of self-employed and paid employees," Small business economics, vol. 40, no. 3, pp. 651-670, 2013.

[41] N. Mustapha, "The influence of financial reward on job satisfaction among academic staffs at public universities in Kelantan, Malaysia," International Journal of Business and Social Science, vol. 4, no. 3, pp. 244-248, 2013.

[42] M. Maguire and B. Delahunt, "Doing a thematic analysis: A practical, step-by-step guide for learning and teaching scholars," All Ireland Journal of Higher Education, vol. 9, no. 3, pp. 3351-33514, 2017.

[43] E. A. Berman, "An Exploratory Sequential Mixed Methods Approach to Understanding Researchers' Data Management Practices at UVM: Findings from the Qualitative Phase," Journal of eScience Librarianship, vol. 6, no. 1, pp. 1-24, 2017.

[44] A. J. Onwuegbuzie and J. P. Combs, "Emergent data analysis techniques in mixed methods research: A synthesis," Handbook of mixed methods in social and behavioral research, vol. 2. Thousand Oaks, CA: SAGE Publications 2010.

[45] C. Teddlie and A. Tashakkori, Foundations of Mixed Methods Research: Integrating Quantitative and Qualitative Techniques in the Social and Behavioral Sciences. Thousand Oaks, CA: SAGE Publications, 2008.

[46] E. Blair, "A reflexive exploration of two qualitative data coding techniques," Journal of Methods and Measurement in the Social Sciences, vol. 6, no. 1, pp. 14-29, 2015.

[47] B. Chamatzkey, "Coding in Classic Grounded Theory: I've Done an Interview; Now What?" Sociology Mind, vol. 6, no. 4, pp. 163-172, 2016.

[48] C.-H. Chong and K.-J. Yeo, "An overview of grounded theory design in educational research," Asian Social Science, vol. 11, no. 12, pp. 258-268, 2015.

[49] R. S. de Avila Soares, et al., "Coding and analyzing data from the perspective of the theory based on data: case report." J Nurs UFPE on line. [Internet], vol. 9, no. 8, pp. 8919-22, 2015.

[50] P. Stern and C. Porr, Essentials of Accessible Grounded Theory. Walnut Creek, CA: Left Coast Press, 2011.

[51] S. Singh, and A. Estefan, "Selecting a Grounded Theory Approach for Nursing Research," Global Qualitative Nursing Research, vol. 5, pp. 1-9, 2018.

[52] K. Kessler and J. J. Braithwaite, "Deliberate and spontaneous sensations of disembodiment: capacity or flaw?" Cognitive Neuropsychiatry, vol. 21, no. 5, pp. 412-428, 2016.

[53] J. C. Scott, "The mission of the university: Medieval to postmodern transformations," The Journal of Higher Education, vol. 77, no. 1, pp. 1-39, 2006.

[54] J. Saldaña, The coding manual for qualitative researchers. Arizona State University, USA: The SAGE Publications, Ltd. 2016.

[55] J. W. Creswell and A. Tashakkori, "Editorial: Differing Perspectives on Mixed Methods Research," Journal of Mixed Methods Research, vol. 1, no. 4, pp. 303-308, 2007. [Online]. Available: https://doi.org/10.1177/1558689807306132

[56] N. Shariff, "Utilizing the Delphi survey approach: A review," J Nurs Care, vol. 4, no. 3, pp. 1-6, 2015.

[57] J. R. Avella, "Delphi panels: Research design, procedures, advantages, and challenges," International Journal of Doctoral Studies, vol. 11, no. 1, pp. 305-321, 2016.

[58] R. A. Green, "The Delphi technique in educational research," Sage Open, vol. 4, no. 2, p. 215824401452977, 2014.

[59] S. Di Zio and A. Pacinelli, "Opinion convergence in location: A spatial version of the Delphi method," Technological Forecasting and Social Change, vol. 78, no. 9, pp. 1565-1578, 2011.

[60] S. S. McMillan, et al., "How to use the nominal group and Delphi techniques," International journal of clinical pharmacy, vol. 38, no. 3, pp. 655-662, 2016.

[61] J. P. Fefer, et al., "Using the Delphi technique to identify key elements for effective and sustainable visitor use planning frameworks," Sage Open, vol. 6, no. 2, pp. 1-16, 2016.

[62] G. Biesta, "Pragmatism and the philosophical foundations of mixed methods research," in Tashakkori, A., and Teddlie, C., Sage handbook of mixed methods in social and behavioral research. Thousand Oaks, CA: SAGE Publications, Inc., vol. 2, pp. 95-118, 2010.

[63] R. B. Johnson and A. J. Onwuegbuzie, "Mixed methods research: A research paradigm whose time has come," Educational Researcher, vol. 33, no. 7, pp. 14-26, 2004.

[64] S. Maxcy, "Pragmatic threads in mixed methods research in the social sciences: The search for multiple modes of inquiry and the end of the philosophy of formalism," in in Tashakkori, A., and Teddlie, C., Handbook of mixed methods in social \& behavioral research, Thousand Oaks, CA: SAGE Publications, Inc., pp. 51-90, 2003. 
[65] D. L. Morgan, "Paradigms lost and pragmatism regained: Methodological implications of combining qualitative and quantitative methods," Journal of mixed methods research, vol. 1, no. 1, pp. 48-76, 2007.

[66] L. D. Pearce, "Mixed methods inquiry in sociology," American Behavioral Scientist, vol. 56, no. 6, pp. 829-848, 2012.

[67] J. N. Hall, "Pragmatism, evidence, and mixed methods evaluation," New Directions for Evaluation, vol. 2013, no. 138, pp. 15-26, 2013.

[68] D. M. Mertens, "Transformative paradigm: Mixed methods and social justice," Journal of mixed methods research, vol. 1 , no. 3, pp. 212-225, 2007.

[69] M. A. Alise and C. Teddlie, "A continuation of the paradigm wars? Prevalence rates of methodological approaches across the social/behavioral sciences," Journal of Mixed Methods Research, vol. 4, no. 2, pp. 103-126, 2010.

[70] M. Q. Patton, Qualitative evaluation and research methods. Sage Publications, Inc., 2002.

[71] D. B. Fishman, "An introduction to the experimental versus the pragmatic paradigm in evaluation," Evaluation and Program Planning, vol. 14, no. 4, pp. 353-363, 1991.

[72] J. Dewey, The later works of John Dewey, 1925-1953: 1925, Experience and Nature. Vol. 1, pp. 1-437. SIU Press, Carbondale: Southern Illinois University Press, 2008.

[73] J. Bethlehem and S. Biffignandi, Handbook of web surveys, vol. 567. John Wiley \& Sons, 2011.

[74] A. Baker, et al., "Feedback and organizations: Feedback is good, feedback-friendly culture is better," Canadian Psychology/Psychologie Canadienne, vol. 54, no. 4, pp. 260-268, 2013. 